\title{
TRADUÇÃO COMENTADA DE LA FORCE DU SERMENT DE AMON D’ABY
}

\author{
A COMMENTED TRANSLATION OF LA FORCE DU SERMENT BY AMON \\ $D^{\prime} A B Y$
}

\section{TRADUCTION COMMENTEE DE LA FORCE DU SERMENT D'AMON D'ABY}

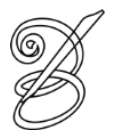 \\ Yéo N'GANA \\ Doutorando em Estudos da Tradução (PGET) \\ Universidade Federal de Santa Catarina (UFSC) \\ Florianópolis, Santa Catarina, Brasil \\ nganayeo@gmail.com
}

Resumo: O presente trabalho é uma tradução comentada do conto La force du serment, do escritor marfinense Amon d'Aby. O objetivo foi analisar, através e pela tradução, tanto as figuras de estilo particularmente nuançadas por um imaginário autoritário que faz refletir sobre a tradução do espaço, quanto os elementos linguístico-culturais presentes no conto.

Palavras-chaves: Tradução. Cultura. Conto. Literatura Marfinense. Amon d'Aby.

Abstract: This work is a commented translation of the tale La force du serment by the Ivorian writer Amon d'Aby. We aimed at analyzing through/by the translation both figures of style particularly framed by an authoritative imaginary requiring that reflections be made on the translation of space, and linguistic and cultural elements found within the tale.

Keywords: Translation. Culture. Tale. Ivorian Literature. Amon d'Aby.

Résumé: Le présent travail est une traduction commentée du conte La force du serment de l'écrivain ivoirien Amon d'Aby. Notre objectif fût d'analyser à travers et par la traduction, à la fois les figures de style présentant des nuances particulières imposées par un imaginaire autoritaire, nous obligeant ainsi à réfléchir sur la traduction de l'espace; et les éléments linguistico-culturels rencontrés dans le conte.

Mots-clés: Traduction. Culture. Conte. Littérature ivoirienne. Amon d'Aby.

"C'est la marque même de l'Afrique noire, où toute parole est poiêsis, c'est-à-dire création."

Léopold Sédar Senghor, p.387

\section{Breve contextualização e bio-bibliografia do autor}

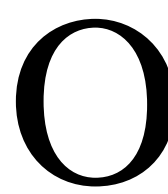

Brasil, como a Costa do Marfimii, é conhecido como grande consumidor de literaturas estrangeiras. Arrisco-me a compará-los, apesar do tamanho continental do Brasil, por causa do cenário linguístico que ambos apresentam. Além da coabitação entre línguas nacionais (Brasil: tupi, guarani, etc./ Costa do Marfim: senufo, diúla, anhi, baúle, etc.) e línguas estrangeiras (alemão, italiano, espanhol, japonês, etc.), cada um 
dos dois países tem uma língua oficial fortemente marcada por regionalismos. Estas características dão rumo a um multiculturalismo que torna o ofício do tradutor complexo e delicado. Estas linhas norteiam minha introdução de ambos obra e autor.

Escritor, dramaturgo e ensaísta, François-Joseph Amon d'Aby ${ }^{\mathrm{iii}}$ nasceu em $1913^{\mathrm{iv}} \mathrm{em}$ Aby, na Costa do Marfim. Este, por sua vez, é um país com aproximadamente 62 línguas nacionais, à exceção do francês, que é a língua oficial. Assim, a obra que nos vai servir de corpus é um texto multívoco marcado pelo "Anhi", língua (não digo dialeto) do autor. Sua compreensão exige do leitor - mesmo do marfinense - um conhecimento sociolinguístico e talvez até etnopragmático. A literatura marfinense é fortemente marcada pela relação línguassociedade-construção de imaginário. Eis uma tarefa muito difícil para um tradutor. Demanda mais do que um simples gênio. Este trabalho é uma reflexão sobre as narrativas africanas, principalmente marfinenses, e sua [in]traduzibilidade.

A(s) literatura(s) africana(s) são por essência orais, pois compostas de cantos, provérbios, enigmas, imagens, entre outros. A particularidade dessas literaturas, por serem orais, é que têm uma certa maleabilidade que a escrita não tem ${ }^{\mathrm{vi}}$. La force du serment é um 108 pequeno conto extraído de um livrinho de quarenta contos. Textos que foram escritos tanto para serem lidos em voz alta como para serem encenados. Na sombra de toda escolha, encontra-se um motivo. Por isso, o nosso interesse em escolher Amon é principalmente devido à figura histórica que ele encarna. Referi-me a 1913 como data de nascimento dele, porém, quando era ainda vivo, afirmava ser mais velho do que o então presidente da república Félix Houphouët Boigny (nascido em 1905). Essa informação ajuda tanto a acompanhar o percurso de Amon, como também a decodificar suas obras, já que seus textos são, ao mesmo tempo, etnosociológicos e literários. Amon d'Aby foi uma figura importantíssima tanto na história geral da Costa do Marfim quanto na construção da sua literatura nacional, e representa também um tipo de ponte intergeracional e inter-cânone. Foi filho da colonização, cresceu em um período no qual a literatura era constituída em geral por relatos (sobre colônias) feitos na sua maioria por colonialistas e exploradores. Formou-se durante a póscolonização $o^{\text {vii }}$, e nessa altura, os escritores africanos [pós-coloniais] tentavam, pelo viés da escrita, resgatar os valores africanos que quase esmoreciam. Preocupavam-se também em construir duas coisas: uma identidade e uma literatura nacionais cujos segredos residiam na tradição. Amon conheceu a independência. Época em que a literatura servia de ferramenta para a resistência. Tratava-se logo de uma literatura de denúncia, uma interminável luta contra o espectro da colonização. A característica comum entre estes dois períodos é o retorno às 
línguas locais, às tradições orais como estilo, que fundamentará minha discussão aqui. Estilo este caracterizado por um casamento quase forçado de duas ou várias línguas (africanas e europeias) nas escritas, nas criações ou recriações à procura de uma estética propriamente africana. Por fim, vivenciou a pós-independência quase como um observador passivo, adoecendo constantemente sob o peso do tempo. Uma literatura determinada por escritas contra as ditaduras e as guerras civis nos países africanos. Os períodos aqui citados influenciaram sua escrita, sua política, suas agendas enquanto literato.

Formado em administração na École Normale William Ponty em Gorée - Senegal, no Institut des Hautes Études d'outre-mer, e capacitado no Centre des Études Administratives sur l'Afrique et l'Asie Moderne; ocupou a posição de diretor dos arquivos nacionais da Costa de Marfim em 1961. Co-fundador do Teatro da Costa do Marfim (1938), participou de um grupo folclórico e escreveu peças de teatro e ensaios sobre os problemas culturais e sociais do seu país. Eleito membro correspondente da Académie des Sciences de l'Outre-Mer, Amon d'Aby também recebe o título de Cavaleiro da Estrela Negra do Benin, e o de Comendador do Mérito da Educação Nacional. Escreveu, entre outros livros: La Côte d'Ivoire dans la cité africaine (1951), Le problème des chefferies traditionnelles en Côte d'Ivoire (1958), Croyances religieuses et coutumes juridiques des Agni de Côte d'Ivoire (1960), La mare aux crocodiles (1973), Le murmure du roi (1984), Les aventures du coq (1985). E as peças de teatro dele: Joseph vendu par ses frères (1941), Kwao Adjoba (1953), Entraves (1955), La couronne aux enchères (1956), La sorcière (1957).

Aqui detive-me em traduzir "La force du serment" extraido de La mare aux crocodiles (1973). Segue o texto:

\section{A tradução de La force du serment ${ }^{\text {viii }}$}

\footnotetext{
Chant

Yé wan yé ndjaman

lé ! lé ! lé !

yé wan yé ndjaman

Allouko é !

Yé wan yé ndjaman

lé ! lé ! lé !

Yé wan yé ndjaman

Yé mé ngnuan

Yé wan yé ndjaman

Yé mé nsan

Yé wan yé ndjaman

Kouan!
}

\author{
Canto \\ Yé wan yé ndjaman \\ lé! lé! lé! \\ yé wan yé ndjaman \\ Allouko é! \\ Yé wan yé ndjaman \\ lé! lé! lé! \\ Yé wan yé ndjaman \\ Yé mé ngnuan \\ Yé wan yé ndjaman \\ Yé mé nsan \\ Yé wan yé ndjaman \\ Kouan!
}


Traduction

Nous avions dit (que) nous ne nous marierions

Jamais ! jamais ! jamais !

Nous avions dit (que) nous ne nous marierions

$$
\text { Allouko é ! }
$$

Nous avions dit (que) nous ne nous marierions

Jamais ! jamais ! jamais !

Nous avions dit (que) nous ne nous marierions Nous deux

Nous avions dit (que) nous ne nous marierions

$$
\text { (jamais) }
$$

Nous trois

Nous avions dit (que) nous ne nous marierions (jamais)

Kouan!

Il était une fois, au pays des morts qu'on appelle aussi Ebbolo, trois jeunes filles liées par une amitié inaltérable. Elles naquirent le même jour, mais de mères différentes. Alloua, Bomo et Ama étaient leurs noms. Et c'était au village d'Amenvi. Elles allaient partout en chantant :

(chant)

Avant même qu'on n'ait fait célébré leur puberté, les prétendants à leur main ne se comptaient plus, tant elles étaient belles. Et la succession des années, loin de ternir leur beauté, ne la rendait que plus éblouissante.

Cependant, la mort qui profane tout icibas, un jour frappa Alloua, et sans même attendre qu'on eût quitté son deuil, emporta aussi Bomo. Ama pleura, pleura, et avec elle toutes les jeunes filles d'Amenvi. Par moments, dans sa tristesse elle murmurait l'air du trio réduit désormais à sa seule voix:

(chant)

Mais tout sur cette terre a une fin, les joies comme les tristesses, et Ama, peu à peu se consola. Chacun l'y aida d'ailleurs du mieux qu'il put ; son père en interdisant l'air qui la faisait pleurer; sa mère et les jeunes filles en lui vantant chaque jour les qualités d'un nouveau prétendant; les enfants en inventant des chansons à la gloire de son incomparable beauté. Bref, le temps à flots sur elle
Tradução

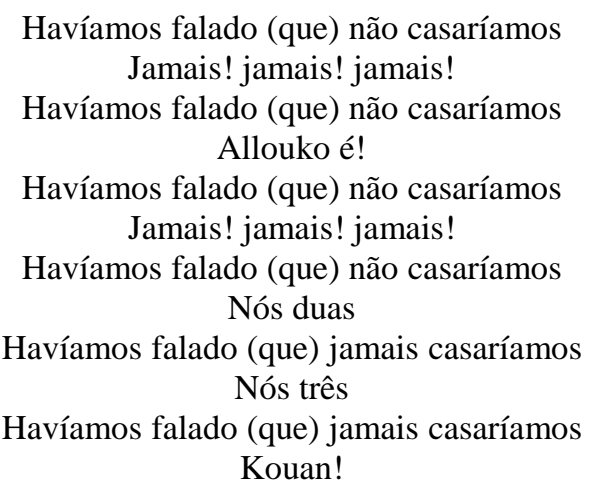

Era uma vez, no país dos mortos, também chamado Ebbolo, três jovem moças unidas por uma amizade inabalável. Nasceram no mesmo dia, de mães diferentes. Allua, Bomo e Ama eram seus nomes . E foi no vilarejo de Amenvi. Elas iam para todos os lugares cantando:

\section{(canto)}

Antes mesmo que tivessem festejado a puberdade, seus pretendentes não se podiam mais contar, tão lindas elas eram. E o passar dos anos, ao invés de ensombrar-lhes a beleza que se tornava ainda mais deslumbrante.

No entanto, a morte que, neste mundo, profana tudo, um dia atingiu Allua, e sem mesmo esperar que a gente terminasse seu luto, levou também Bomo. Ama chorou, chorou, e com ela, todas as jovens moças de Amenvi. Às vezes, na sua tristeza, murmurava a canção das três agora resumida na sua voz só:

(canto)

Mas tudo nesta terra tem um fim, alegrias e tristezas, e Ama, pouco a pouco se consolava. Cada um, a propósito, a ajudou como pôde; seu pai moldando a atmosfera que a fazia chorar; sua mãe e as jovens moças vangloriando cada dia as qualidades de um novo pretendente ; as crianças inventando canções para exaltar sua incomparável beleza. Em resumo, com o tempo, tomaram conta dela, a embriaguez e o esquecimento 
versa l'ivresse et l'oubli tant et si bien que cédant à la douce pression des parents, elle se maria avec le jeune prince et se laissa conduire au palais, escortée par une multitude de servantes dévouées. Au palais, on n'accédait à son appartement privé qu'après avoir traversé six portes bien gardées.

\section{(chant)}

Bientôt, certains signes infaillibles indiquèrent qu'Ama était enceinte et la cour attendait dans la joie la naissance de l'enfant royal. C'est ce moment précis que la mort choisit pour dépêcher auprès d'elle sa fidèle et obéissante messagère, la fièvre. Elle arriva un soir au galop et ne voulut plus la quitter. Alors l'émotion s'empara de la cour et de la cité d'Amenvi.

La malade s'étant par trois fois évanouie en une seule nuit, le roi fit mander d'urgence le féticheur Assem-Kora. Chaque fois qu'il arrivait devant une porte, Assem-Kora s'arrêtait pour invoquer ses génies. Quand s'ouvrit enfin la dernière porte, il entonna un chant que la malade, au grand étonnement de la cour, reprit avec une joie visible.

\section{(chant)}

«Miracle! c'est la guérison! » se disait-on déjà. Or, ce n'était ni un miracle, ni la guérison, mais plutôt les adieux de la belle Ama avec ce monde. En effet, à la fin du chant, sa voix se tut pour toujours.

Que s'était-il passé ? On la sut par le féticheur : Ama avait été rappelée au royaume des morts pour avoir violé le serment qu'elle fit de ne jamais se marier. Et ce fut par la faute de ses parents.

C'est pourquoi la sagesse recommande de ne pas trop insister quand une fille n'a pas envie de se marier.

(1) Nous avions dit, entendez nous avions juré, nous avions promis

(2) Allouko : nom du témoin du serment des trois jeunes filles

(3) Onomatopée : bruit produit par une porte qui geint. de tal forma que cedeu à paciente pressão dos pais, casou-se com o jovem príncipe e deixou-se levar para o palácio escoltada por uma multidão de servas devotas. No palácio, obtinha-se acesso ao seu apartamento privado somente após se ter atravessado seis portas bem protegidas.

(canto)

Logo, alguns sinais infalíveis mostraram que Ama estava grávida e a corte esperava na alegria o nascimento do bebê real. Foi esse o preciso momento escolhido pela morte para lhe enviar sua obediente e fiel mensageira, a febre. Numa tarde, a galope, chegou e não quis mais deixá-la. Então a emoção tomou conta da corte e da cidade de Amenvi.

Como a doente havia desmaiado três vezes numa só noite, o rei mandou chamar urgentemente Assem-Kora, o curandeiro. Cada vez que chegava diante de uma porta, Assem-Kora parava para invocar seus espíritos. Quando finalmente abriu-se a última porta, entoou um canto que a doente, para o grande espanto de todos, retomou com uma alegria visível.

(canto)

“Milagre! é a cura!", dizia-se já. Porém não era nem milagre, nem cura, mas ao contrário os adeuses da bela Ama para com este mundo. Com efeito, no fim da canção, sua voz calou-se para sempre.

O que tinha acontecido? Soubemos através do feiticeiro: Ama tinha sido chamada de volta ao reino dos mortos por ter desrespeitado o juramento que fez de nunca se casar. E a culpa foi de seus pais.

É por isso que o bom senso recomenda não insistir quando uma moça não quer se casar.

(1) Tínhamos falado, quer dizer, tínhamos jurado, tínhamos prometido

(2) Allouko : nome da testemunha do juramento das três jovens moças

(3) Onomatopéia : ruído produzido por uma porta grunhindo. 


\section{La force du serment: entre transferências e inferências}

Partindo do princípio de que para transferir é preciso ter ou saber o que se transfere, o resultado desta tarefa árdua - antigamente ofício dos griô ${ }^{\mathrm{ix}}$, e hoje da responsabilidade dos tradutores - deverá seu devir à notoriedade, ao literalismo e ao conhecimento do tradutorleitor principalmente das línguas e culturas de partida. Hampâté Ba defendia que

o que está causa por trás do testemunho em si é, pois, o próprio valor de quem testemunha, o valor da rede de transmissão à qual ele está atrelado, a fidelidade da memória individual e coletiva e a importância dada à verdade em determinda sociedade $^{\mathrm{x}}$. (HAMPÂTÉ BA, 1999, p.192; tradução nossa)

O desafio é sem dúvida óbvio, uma vez que o próprio Amon d'Aby teve que deixar a palavra "allouko" na versão em francês do canto para explicá-la em nota. "Douce", na frase “...l'oubli tant et si bien que cédant à la douce pression des parents...” carrega a ideia de algo que se faz com continuidade, sem brutalidade. Uma pressão - conforme aparece na frase que nos parece afiliar-se ao tempo, e dele tira sua força. Um tempo parceiro, um tempo resistente, o tempo das coisas. O simples fato de se pensar em pressão, física ou não, já é psicologicamente doloroso. Essencial neste processo de compreensão foi adentrar o próprio mundo das palavras para com elas conversar, questionar seu intento, pois na sombra delas, se escondem as intenções e o projeto do autor. No entanto, a falta de intimidade do tradutorleitor com o texto de partida pode resultar do diálogo enviesado, muitas vezes, pela sua posição quer política, quer literária. Isso pode, de muito, contribuir para sua incapacidade em reproduzir a [suposta] intenção do texto ${ }^{\mathrm{xi}}$. O oximoro "Douce pression" em português faz lembrar figuras de linguagem como música silenciosa, obscura claridade. Embora as duas palavras aparentem o paradoxo ou o eufemismo, reforçam-se mutuamente. "Douce" ou doce em português adquire seu efeito de modo gradativo, com lentidão, com suavidade, com jeito e tempo. O tempo coloca-se tanto como juiz quanto como agente na corporificação do resultado, o que requer paciência. Nos dois termos "douce” e "pression", espera-se um resultado evidenciando a ideia de reforço ou de complementaridade supramencionada. $\mathrm{O}$ vocábulo "paciência" me parece acoitar-se nas duas palavras, portanto a minha escolha paciente pressão.

Outra palavra que merece destaque na análise é "appartement". O primeiro sentido de "appartement" poderia ser apartamento, entretanto, pelo texto ter sido escrito em contexto e lugar específicos, ambos condicionados por uma cultura específica, torna-se necessário levar em conta o referente, o próprio signo linguístico. Se a significação pode ser concebida como 
um processo, é o ato que une o significante e o significado ${ }^{x i i}$. O significado em algumas narrativas africanas pode parecer um pouco vago ou quase superficial para o leitor-tradutor leigo que desconhece o funcionamento do falar africano específico no texto.

O que faria um tal tradutor-leitor, a não ser interpretar o texto a traduzir? Torna-se obviamente desafiante fazer uma inferência qualquer, especialmente quando "os factos só são verdadeiros depois de serem inventados"xiii. A relação aqui estabelecida com a obra de Mia Couto parece essencial. No último voo do flamingo (2015), o narrador - tradutor - e personagem principal mostra claramente o chamativo papel da cultura no processo de tradução, consequentemente na comunicação entre os personagens. Contador de histórias, Mia Couto pode ser considerado tradutor no caso da África, pois ele passa histórias que lhe foram contadas da fala para a escrita. Isso constitui em si uma tradução, isto é, a passagem de um sistema (oral) para outro (escrita) permeada por operações intra e intercódigos (PLAZA, 2010, p. XII). Para esses escritores africanos, o psiquismo ocupa um lugar privilegiado e ajuda o tradutor-leitor na construção do sentido. Na sua obra, o narrador-tradutor informa o italiano para quem estava traduzindo da existência de três vilas: Tizangara-terra, Tizangaracéu, Tizangara-água ${ }^{x i v}$, e pede-lhe para escolher aquela que queria visitar. Aqui, no meu trabalho, "Il était une fois, au pays des morts qu'on appelle aussi Ebbolo...", isto é, "Era uma vez, no país dos mortos, também chamado Ebbolo..." é um indicador muito importante, pois ajuda o leitor, e no caso o tradutor, na formação do imaginário que aparece aqui como uma conditio sine qua non para penetrar e compreender o universo do texto.

Como traduzir palavras que foram cuidadosamente escolhidas e dirigidas para um público predefinido? Como fazer dialogar um texto com um público cujo imaginário é outro? Eis onde o tradutor há de usar sua criatividade, submetendo a palavra ora para turvar, ora para reforçar ou retirar as fronteiras geográficas, linguísticas ou culturais entre Texto de Partida Texto de Chegada, Cultura de Partida - Cultura de Chegada, Língua Partida - Língua de Chegada. No entanto, para Tymoczko

\footnotetext{
Insistir num entre existente em relação às línguas seria abandonar o consenso da modernidade acerca dos sistemas. Tal concepção de um entre, que ocorre na tradução de uma língua ou de uma cultura para a outra, vistas como sistemas é, portanto, incompatível com uma visão das próprias línguas como sistemas formais que, na realidade, constroem significados ao invés de consistirem em estruturas que meramente refletem significados extralinguísticos. (TYMOCZKO, 2013, pp. 137138)
} 
A presença da ideologia fazendo-se cada vez mais presente no processo de tradução e/ou produção literária: é onde o sentido não mais depende da palavra. No entanto, No último voo do flamingo, Couto deixa clara a filosofia tizangarense na narrativa ao dizer que "cada coisa tem direito a ser uma palavra. Cada palavra tem o dever de não ser nenhuma coisa"xv . Vê-se então o quanto a procura por uma referencialidade, ou seja, por uma equivalência na língua portuguesa poderá ser um dos mais complicados desafios para o tradutor. Conforme disse Paulo Rónai na sua obra Tradução vivida,

o bom tradutor, depois de se inteirar do conteúdo de um enunciado, tenta esquecer as palavras em que ele está expresso, para depois procurar na sua língua, as palavras exatas em que semelhante ideia seria naturalmente vazada. (RONAI, 1981, p.58)

Embora a expressão "esquecer as palavras" de Rónai fortaleça a morte do texto (de partida) - quer silenciado ou enforcado pelo tradutor iniciante, quer saboreado e preciosamente guardado pelo tradutor experiente - , o parágrafo resume a fala de García Yebra $^{\text {xvi }}$ de que a tradução consiste em compreensão e expressão. Essas duas noções no texto de Amon d'Aby inscrevem-se em uma discussão sobre a própria concepção não eurocentrista, mas africana do que é case, maison, appartement, bidonville, taudis, baraque, cabane, masure, hutte, bâtiment, édifice, bâtisse, construction, monument, chez-soi, foyer, toit. Entretanto, o contexto atual muda por completo a nossa abordagem do assunto. Porquanto estamos em uma relação dialógico-cultural entre duas "ex-colônias". As diferenças ecológicas se houvesse referências à neve ou às estações do ano ficariam talvez mais evidentes se se tratasse de uma relação Europa-África. Pois se tornou tão erroneamente frequente referir-se às "ex-colônias" como um todo, como uma mesma e única coisa. Todavia, o texto de Amon d'Aby, identificado como um conto, de início, situa bem o contexto com "era uma vez no país dos mortos". O caráter patafísico do texto aumenta a subjetividade na interpretação. A tradução da palavra "appartement" demandaria que soubéssemos da história dos dois povos. Para Berman, um tradutor sem consciência histórica é um tradutor mutilado, prisioneiro da sua representação do traduzir e daquelas que veiculam os [discursos sociais] da época ${ }^{\mathrm{xvii}}$. Apesar da experiência colonial que o Brasil e a África partilham, que favoreceu a introdução de crenças africanas na construção da cultura brasileira, a palavra féticheur em "le roi fit mander d'urgence le féticheur Assem-Kora", apresenta ainda ambiguidades. A própria raiz "fétiche" pode também ser relacionada ao erotismo. Assim, traduzir féticheur por "fetichista" poderá deixar o leitor confuso. Com a definição de "Feiticeiro" pelo dicionário Michaelis ${ }^{x v i i i}$ como um substantivo masculino referente àquele que faz feitiços, um bruxo, perde-se a ideia 
de salvação. Por isso, resolvi escolher a palavra curandeiro também pela proximidade semântica com "médico" (principalmente entre os africanos). É importante mencionar que a irracionalidade, a existência de poderes sobrenaturais constitui o eixo comum entre as três palavras. Embora fetichista apareça no dicionário eletrônico Houaiss ${ }^{\mathrm{xix}}$ como "aquele que cultua fetiche(s), como referente a ou próprio de fetichismo", a tradução ficou : o rei mandou chamar urgentemente Assem-Kora, o curandeiro.

\section{Tradução do canto}

$\mathrm{Na}$ cultura ou mitologia Anhi, os cantos, provérbios, parábolas participam da construção da poética, da estrutura das narrativas. Para eles, morrer é passar para outro estado da vida. Os mortos não são mortos. Ao contrário, são eles quem têm o segredo da tradição, são guardiões dos valores, pois "na África, o que está escondido é mais profundo e mais real do que está visível"xx. Cantos, provérbios e narrativas são tentativas de exaltação, de reverência a eles. Essas louvações da onipresença dos ancestrais entre os "Anhi" reduz as fronteiras entre o visível e o invisível. Em Liberté 3 : Négritude et civilisation de l'universel, Senghor (1977) argumenta que os provérbios africanos, assim como qualquer outro gênero literário de origem oral, mantêm sua forma original, isto é, a de um poema. Consequentemente, o canto aqui presente tem a estrutura de um poema. Composto por ideofones $^{\mathrm{xxi}}$ oriundo do Anhi, é um poema muito sonoro. Ele deixa visíveis as rimas externas de fim de versos. Interessante é que - por se tratar de uma língua complexa - o próprio autor resolveu transcrever as frases "Anhi" para o francês. Embora quase todos os versos tenham o mesmo fim, à exceção dos versos 2, 4 e 6, perde-se a lógica e a sonoridade na tradução para o francês. De [lé ! lé ! lé ! ], [ Allouko é ! ], [ lé ! lé ! lé ! ] chegamos a Jamais! Jamais! Jamais! Allouko é! Jamais! jamais! jamais! Mantive também Allouko por ser um nome próprio. Em português, tentei criar uma aliteração em "c" para compensar a perda do som "é" do canto em língua anhi:

Yé wan yé ndjaman
lé ! lé ! lé !
yé wan yé ndjaman
Allouko é !
Yé wan yé ndjaman
lé ! lé ! lé !
Yé wan yé ndjaman
Yé mé ngnuan
Yé wan yé ndjaman
Yé mé nsan
Yé wan yé ndjaman
Kouan!

Yé wan yé ndjaman wan yé ndjaman Allouko é ! wan yé ndjaman Yé wan yé ndjaman Yé mé ngnuan Yé mé nsan Kouan!
Nous avions dit (que) nous ne nous marierions Jamais ! jamais! jamais!

Nous avions dit (que) nous ne nous marierions Allouko é !

Nous avions dit (que) nous ne nous marierions Jamais ! jamais ! jamais !

Nous avions dit (que) nous ne nous marierions Nous deux

Nous avions dit (que) nous ne nous marierions (jamais)

Nous trois

Nous avions dit (que) nous ne nous marierions
Combináramos que casamento Nunca! Nunca! Nunca! Combináramos que casamento Allouko é!

Combináramos que casamento Nunca! Nunca! Nunca!

Combináramos que casamento nunca

Nem eu nem tu

Combináramos que casamento nunca Nós três 
No que diz respeito à onomatopeia "kouan" e ao nome "Alloua", optei por kuã e Allua, fazendo uma aproximação morfofonológica como foi o caso com a palavra "agni", que ficou anhi.

Muitas vezes, não será possível ao tradutor dominar com maestria todos os contornos das línguas encontradas no texto. Alguns confiarão na única proposta feita pelo escritor como foi o caso neste texto - e outros, em uma tentativa meio desesperada (coibidos pelo prazo ou por falta de informações ao alcance), deixar-se-ão cair em uma série de interpretações com um risco de apagamento da história. Traduzir as narrativas africanas embora não seja impossível, requer, portanto, que o tradutor-leitor procure não se limitar às cascas das palavras, senão ir-se além. Ele há, por isso, de casar-se com a filosofia africana contida na obra para poder penetrar a alma das palavras.

\section{REFERÊNCIAS}

AKROBOU, Ezechiel. Traduire la littérature africaine francophone, entre oralité et écriture: cas du roman Les Soleils des indépendances, d'Ahmadou Kourouma. In: Estudios de Traducción. Madrid, vol. 22, 2012, pp.77-86.

BARRETO, Junia. Nota da tradutora. In: DERRIDA, Jacques. Torres de Babel. Belo Horizonte: Editora UFMG, 2006.

BARTHES, Roland. Elementos de semiologia. Trad. Izidoro Blikstein. 19a Ed. São Paulo: Editora Cultrix, 2012.

BERMAN, Antoine. Pour une critique des traductions: John Donne. Paris : Gallimard, 1995.

BUCKLEY, Thomas. Oralité, distance sociale et universalité. In: BALLARD, Michel (Éd.). Oralité et Traduction. Arras: Artois Presses Université, 2001, pp. 265-278.

D'ABY, Amon. La force du serment. In: La mare aux crocodiles. Abidjan: CEDA NEA, 1992, pp. 65-67.

HAMPATE BA, Amadou. "La tradition vivante". In: Joseph Ki-Zerbo (Éd.), Histoire générale de l'Afrique: I. Méthodologie et Préhistoire Africaine. Paris : Unesco, 1999, pp. $191-230$

PLAZA, Julio. Tradução intersemiótica. 2a Ed. São Paulo: Perspectiva, 2010. 
RONAI, Paulo. A tradução vivida. $3^{\text {a }}$ Ed. Rio de Janeiro: Nova Fronteira, 1981.

SENGHOR, Léopold Sédar. Quand le proverbe est poésie. In: Liberté 3 : négritude et civilisation de l'universel. Paris: Le Seuil, 1977, pp. 387-388.

TYMOCZKO, Maria. Ideologia e a posição do tradutor: em que sentido o tradutor se situa no “entre”(lugar)? In: FRIESEN B, Rosvitha; PETERLE, Patricia (Orgs.). Tradução e Relações de poder. Tubarão: Copiart, 2013, pp. 137-138.

ZAHAN, Dominique. Sociétés d'initiation bambara: Le N'domo, le Korè. In: OUEDRAOGO, Amadou. L'imaginaire dans l'esthétique romanesque de Jean-Marie Adiaffi : une lecture de La carte d'identité. Paris: L'Harmattan, 2015.

\footnotetext{
i Yeo N'GANA - Graduado em Letras (Português (2010) e Metes em Lietratura/Linguística (2014), ambos pela Universidade Félix Houphouët-Boigny. Bolsista CAPES-DS.

Currículo Lattes Yeo N'Gana. Disponível em: http://lattes.cnpq.br/0963580215204979

ii Como a maioria dos diversos países africanos.

iii Biografia do autor: http://www.academieoutremer.fr/academiciens/fiche.php?aId=1 https://fr.wikipedia.org/wiki/Fran\%C3\%A7ois-Joseph_Amon_d'Aby

iv Ver a biografia do autor: http://www.academieoutremer.fr/academiciens/fiche.php? $\mathrm{aId}=1$ <https://fr.wikipedia.org/wiki/Fran\%C3\%A7ois-Joseph_Amon_d'Aby>

v A ortografia da palavra em francês é "agni". Escolhemos representá-la assim seguindo critério morfofonológico.

vi BUCKLEY, 2001, p. 265.

vii Refiro-me aqui ao período de descolonização que compreendeu os anos 1945 a 1960.

viii D’ABY, Amon. La force du serment. In: La mare aux crocodiles. Abidjan: CEDA NEA, 1992, pp.65-67.

${ }^{i x}$ Mestres da palavra nos reinos africanos.

${ }^{\mathrm{*}}$ "Ce qui est en cause derrière le témoignage lui-même, c'est donc bien la valeur même de l'homme qui témoigne, la valeur de la chaîne de transmission à laquelle il se rattache, la fidélité de la mémoire individuelle et collective et le prix attaché à la vérité dans une société donnée. »(HAMPÂTÉ BA, 1999, p.192)

${ }^{x i}$ BARRETO, 2006, p. 7.

xii BARTHES, 2012, p. 61.

xiii COUTO, Mia. O último voo do flamingo. São Paulo: Companhia das Letras, 2015, p. 67.

xiv COUTO, 2015, p. 105.

${ }^{\mathrm{xv}}$ COUTO, 2015, p. 135.

xvi YEBRA, García apud AKROBOU, 2012. p. 82.

xvii BERMAN, 1995, p.61.

"Un traducteur sans conscience historique est un traducteur mutilé, prisonnier de sa représentation du traduire et de celles que véhiculent les « discours sociaux » du moment".

xviii Disponível em: http://michaelis.uol.com.br/moderno/portugues/index.php?lingua=portuguesportugues\&palavra=feiticeiro. Acesso 27/06/16 às 12:55.

xix INSTITUTO ANTÔNIO HOUAISS. Dicionário electrônico: Houaiss da língua portuguesa. Rio de Janeiro: Editora Objetiva, 2001.

xx ZAHAN, 2015. "En Afrique, ce qui est caché est plus profond et plus vrai que ce qui est visible", p. 43.

${ }^{x x i}$ Conceitos que não desenvolveremos aqui por uma questão de objetividade.
}

RECEBIDO EM: 02 de setembro de 2016

ACEITO EM: 23 de novembrob de 2016

PUBLICADO EM: Dezembro de 2016 